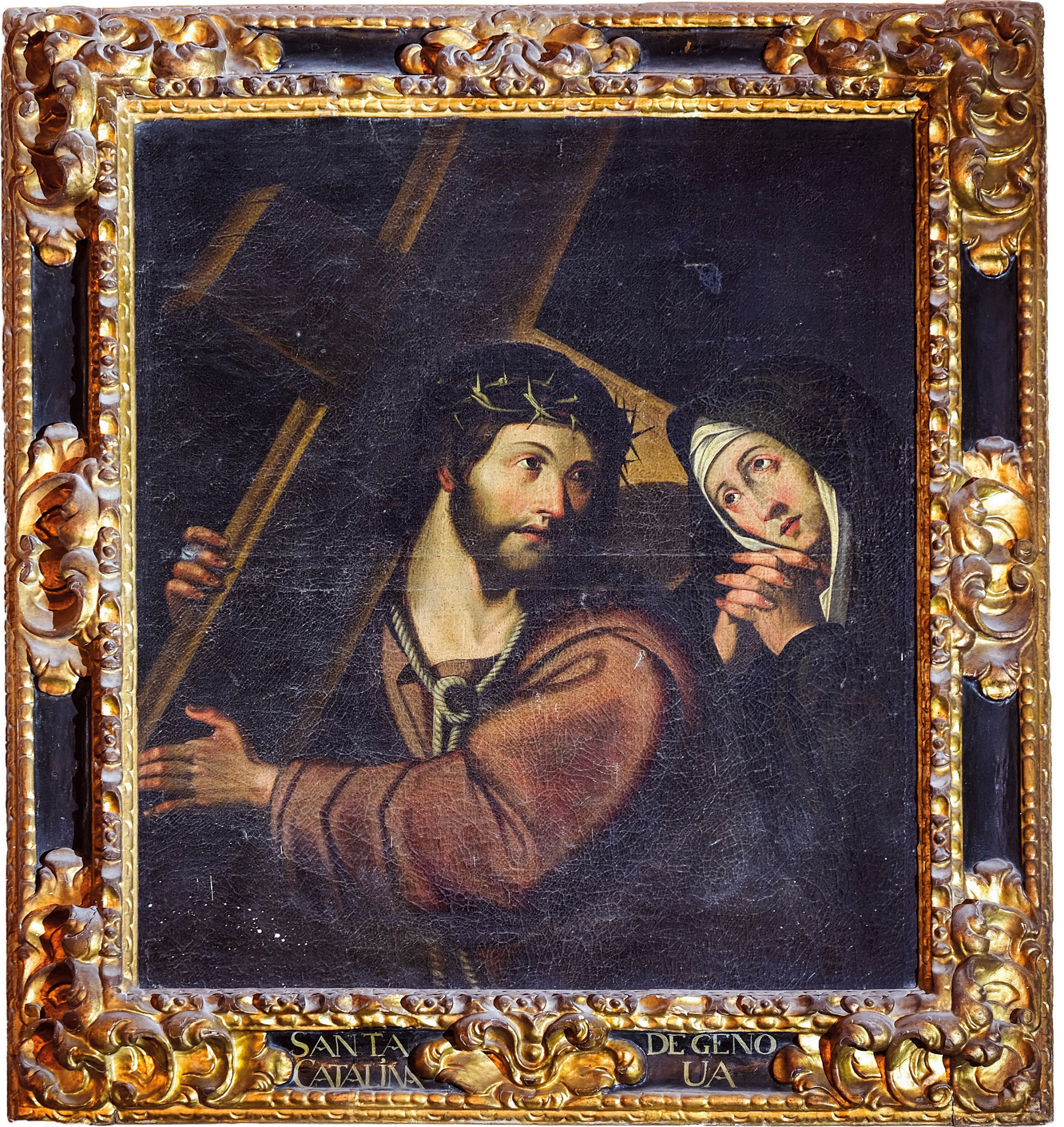

Fig. 1. Encuentro de Jesús y la Virgen camino del Calvario, Iglesia Mayor de Sanlúcar de Barrameda ¿poco después de 1607? ¿Francisco Pacheco? Foto de Óscar Franco ๑. 


\title{
Una copia española del Camino al Calvario de Scipione Pulzone
}

\author{
A Spanish copy of The Road to Calvary by Scipione Pulzone
}

\author{
Antonio Romero Dorado \\ Universidad de Sevilla, España \\ antonio.romero.dorado@gmail.com \\ https://orcid.org/0000-0002-4979-0491
}

\section{Resumen}

El texto presenta una copia del Camino al Calvario de Scipione Pulzone conservada en la Iglesia Mayor de Sanlúcar de Barrameda (España). Se trata de una versión simplificada de la citada obra, realizada al "gusto español" por un artista sevillano, posiblemente Francisco Pacheco, bajo el patrocino artístico de la Casa de Medina Sidonia.

Palabras clave: Scipione Pulzone; Il Gaetano; copias pictóricas; pintura italiana en España; Francisco Pacheco; Sanlúcar de Barrameda; Casa de Medina Sidonia.

\begin{abstract}
This paper presents a copy of The Road to Calvary by Scipione Pulzone preserved at the Major Church of Sanlúcar de Barrameda (Spain). It is a simplified version of the aforementioned painting, which was apparently painted by a Sevillian artist, possibly Francisco Pacheco, under the artistic patronage of the House of Medina Sidonia. The resulting painting shows a sobriety and pathos that are usually related to the so-called "Spanish taste".

Keywords: Scipione Pulzone; Il Gaetano; Pictorial copies; Italian painting in Spain; Francisco Pacheco; Sanlúcar de Barrameda; House of Medina Sidonia.
\end{abstract}


La Iglesia Mayor de Sanlúcar de Barrameda (España) alberga un interesante conjunto de pinturas de caballete del primer tercio del siglo XVII. Como es sabido, este fue un momento clave en la historia de la pintura sevillana y espańola, en que se recibieron las revolucionarias novedades de la pintura italiana, fundamentalmente, tenebrismo y naturalismo. Sin embargo, en este periodo continuó la admiración por los maestros manieristas italianos y, en consecuencia, el copiado de obras tardomanieristas. Dentro de ese fenómeno, queremos dar a conocer aquí una copia del Camino al Calvario que Scipione Pulzone (1544-1598) realizó hacia 1581-1583 para el III duque de Paliano, Marcantonio Colonna ${ }^{1}$.

El Encuentro de Jesús y la Virgen de camino al Calvario de la Iglesia Mayor de Sanlúcar (Figs. 1 y 2), es una pintura al óleo sobre lienzo, de aproximadamente $125 \times 115 \mathrm{~cm}$, con marco. Sobre un fondo completamente negro, se muestran las imágenes de medio cuerpo de Cristo y de su madre en el Via Crucis. Casi en el centro de la composición aparece Jesús, que lleva la cruz a cuestas y ciñe la corona de espinas. Asimismo, está vestido con una túnica morada de matiz parduzco y peculiares pliegues. Lleva al cuello una cuerda gruesa, anudada a la altura del pecho y que le cae por delante del torso. A su derecha, muy pegada a su hijo, se ve a la Virgen María, ataviada con toca blanca, túnica azul oscuro y manto del mismo color. Sus manos, colocadas junto al rostro, se entrelazan en un gesto que mezcla el dolor, la súplica y la impotencia. Las manos de Cristo, por su parte, abrazan con firmeza la cruz, cuyos volúmenes se han plasmado recurriendo a diferentes marrones y a varias luces y sombras, destacando la que proyecta la cabeza del nazareno. Jesús vuelve su rostro hacia atrás para buscar el de su madre, mientras esta ladea el suyo con ternura. La inclinación de las cabezas, su proximidad y el intenso intercambio de miradas, dotan a la escena de un gran patetismo, equilibrado por la simetría existente entre las caras. El tratamiento de los rostros y las manos es extremadamente delicado, para recreo del espectador. Esto se debe al perfecto acabado de las carnaciones y sobre todo por el uso de sutiles veladuras, que ruborizan la piel de los protagonistas en determinadas zonas, mostrando los efectos del sufrimiento y del llanto. Asimismo, se han usado veladuras para ir formando las uñas de la Virgen, la barba de Cristo y las pequeńas gotas y regueros de sangre causados por las espinas. Del mismo modo, es exquisito el tratamiento de los labios, que dejan entrever los dientes. No obstante, el verdadero núcleo dramático de la obra está en los ojos de madre e hijo. Para acabar la descripción, hay que decir que la pintura está encuadrada en un marco negro y dorado que presenta partes lisas y otras talladas con motivos vegetales. Su estilo es barroco y puede fecharse en la segunda mitad del siglo XVII ${ }^{2}$. Además, en la parte inferior del marco puede leerse la siguiente leyenda: "SANTA CATALINA DE GÉNOVA", en letras doradas sobre fondo negro, lo que da a entender que se trata de un marco reutilizado.

El estado de conservación de la obra parece aceptable, aunque a simple vista se observan algunos problemas. El roce de la madera del bastidor y del travesaño central sobre el lienzo ha producido micropérdidas en la capa pictórica. Los márgenes del lienzo podrían haber sido ligeramente recortados para adaptarlos al marco o, al menos, este parece tapar parcialmente los dedos de una de las manos de Cristo. Por encima de la cabeza de la Virgen, sobre el fondo negro, hay una pequeña pérdida de la capa pictórica, que quizá se debiera a una rotura del lienzo. Esta pérdida parece que se ha repintado sin haber aplicado una base de estuco, por lo que está ligeramente hundida. Toda la superficie se ha craquelado en mayor o menor medida, lo que sin

1. Queremos agradecer las facilidades dadas para estudiar la obra al sacerdote D. Juan Jacinto del Castillo Espinosa, que fue párroco de la Iglesia Mayor de Sanlúcar desde 2010 hasta 2017. Asimismo agradecemos a D. Óscar Franco sus magníficas fotografías y entusiasmo.

2. Debemos y agradecemos su opinión respecto a la cronología del marco a D. José Manuel Moreno Arana. 
embargo no afecta a la lectura de la obra. Por último, se aprecian bastantes salpicaduras de pintura blanca y mucho polvo.

Como hemos dicho, esta pintura es una copia del Camino al Calvario que Scipione Pulzone realizó hacia 1581-1583 para el III duque de Paliano, Marcantonio Colonna. La obra original, cuyo paradero se ha ignorado durante casi cuatro siglos, se conoció hace unos años gracias a una versión aparecida en Varese, que fue adquirida por el Anticuario Giovanni Minozzi, de Milán. En 2012 fue dada a conocer por Antonio Vannugli ${ }^{3}$, junto a un estudio gracias al cual conocemos bastantes aspectos de la historia de la pintura original, que nos permiten contextualizar la pintura de Sanlúcar. Como se ha dicho, el original fue encargado por el III duque y I príncipe de Paliano, que era súbdito del rey Felipe II de España y virrey de Sicilia desde 1577. Paliano lo regaló en 1583 al secretario del rey, Mateo Vázquez de Leca (1542-1591). A la muerte de este, lo recibió en herencia su sobrino, de igual nombre, que era arcediano de Carmona en la catedral de Sevilla, ciudad a la que el cuadro llegó en 1607 desde la Corte. En Sevilla lo vio Francisco Pacheco, quien lo elogió con entusiasmo por su gran preciosismo, describiéndolo con mucho detalle en su Arte de la pintura.

En palabras del pintor es "un Cristo con la cruz a cuestas [...] y la Virgen Nuestra Señora [...]. Está mirando con grave y varonil compasión el Redentor a la Sagrada Virgen, y ella a él, con tanto afecto y ternura que moverán a piedad las piedras. Donde, maravillosamente, ejecutó el pintor la semejanza del rostro del Hijo y de la Madre, particularmente en los ojos, que, a mi ver, no se ha pintado cosa más viva, o no he visto (por decirlo mejor) de ningún artifice, ojos que asi me admiren. Vese el acabado de la barba del Salvador con tanta paciencia que en su sutileza de pelo sobra a las pinturas de Alberto Durero (por decir más que de Morales). Pues las manos del Señor, con que abraza la cruz, son de hombre vivo; parecen en ellas las varias tintas que hace la carne natural, y la distinción del color de ella y de las uñas con tanto primor que no puede ser más. Es pintura de dientes y uñas porque se defiende con la dificultad de su acabado, que es tal, que el madero de la cruz, teniendo la mano sobre ély tocando el lienzo, todavia está un hombre dudoso si es natural o pintado. Cuando vi esta pintura dije, osadamente, como aqui, mi sentimiento"s.

La relación de Pacheco con el arcediano de Carmona es bien conocida, pues el pintor sanluqueño policromó el Crucificado de la Clemencia, esculpido por Juan Martínez Montañés por encargo del eclesiástico. Además, Pacheco pintó la llamada Inmaculada de Vázquez de Leca, donde incluyó el retrato del arcediano y que se conserva en la colección del marqués de la Reunión 5 . Además del Camino al Calvario, que llegó a Sevilla tras haber estado en Roma, Palermo y la Corte española, hubo otra versión del mismo asunto pintada por el propio Pulzone de forma casi simultánea. En esta ocasión el comitente fue el cardenal Ferdinando de Medici, que después llegó a ser III Gran Duque de Toscana. Parece que el cardenal Medici también quiso enviar su réplica a España, al mismo secretario del rey, pero finalmente cambió de planes al saber que Colonna ya lo había hecho. Lo cierto es que esta versión figura en los inventarios desde 1588 y estuvo en la Villa Medici del monte Pincio de Roma, al menos desde 1620 y luego fue transferida al Palazzo Madama de la misma ciudad 6 .

3. VANNUGLI, Antonio, "La subida al Calvario de Scipione Pulzone para Marcantonio Colonna", Archivo Español de Arte, vol. 85, n. ${ }^{\circ}$ 340, 2012 , págs. $303-328$.

4. PACHECO, Francisco, Arte de la Pintura, Sevilla, 1649, fols. 320-321.

5. VALDIVIESO GONZÁLEZ, Enrique y SERRERA CONTRERAS, Juan Miguel, Pintura sevillana del primer tercio del siglo XVII, Madrid, Consejo Superior de Investigaciones Científicas, 1985, pág. 69.

6. VANNUGLI, Antonio, "La subida al Calvario...", op. cit. 
La identificación de la obra realizada por Vannugli en 2012, ha permitido que en los años posteriores se hayan identificado en España otras versiones de la obra y algunas copias. De todas ellas se ha hablado recientemente $^{7}$ y destacan por su calidad los ejemplares localizados en las galerías Caylus de Madrid e Isbilya de Sevilla, y en la Iglesia de la Hermandad de San Hermenegildo de esta última ciudad, que parecen obras autógrafas o del taller de Pulzone. A estas se añade una quinta versión conservada en el Museo de Bellas Artes de Budapest ${ }^{8}$. Si comparamos estas cinco versiones, podemos establecer dos grupos. Por un lado, la pintura de Budapest, la de la Iglesia de San Hermenegildo y la subastada por Isbilya en 2016 y, por otro, la dada a conocer por Vannugli en 2012 y la de la Galería Caylus. En el primer grupo observamos que la túnica de Cristo tiene un color rosáceo y un acabado satinado similar. Por el contrario, en el segundo esa túnica es roja. Asimismo, en el paisaje de fondo, en el primer grupo vemos la puerta de una muralla con figuras delante que no aparece en el segundo. Otra diferencia entre grupos son los lazos negros que están en el chaleco amarillo del sayón que aparece de espaldas, que solo están en el segundo.

Esta homogeneidad existente dentro de ambos grupos, se rompe en dos detalles. El primero es un sayón con casco que está situado entre las cabezas de la Verónica y de San Juan. Este personaje puede verse en todas las versiones salvo en la de Isbilya. El segundo es el rostro togado de una santa mujer que está a la derecha de San Juan, que solo aparece en la versión de San Hermenegildo. Pero lo que más nos interesa para nuestro estudio son los pliegues de la túnica de Cristo, cuya morfología difiere significativamente entre los dos grupos, presentando la copia de Sanlúcar una configuración similar a los pliegues del primer conjunto. Por ello, teniendo en cuenta que la copia que presentamos debió de ser realizada en Sevilla, a partir de la primera versión de Pulzone, propiedad de Vázquez de Leca, opinamos que esa primera versión pudo ser la conservada en Budapest, a juzgar por el característico pliegue que tiene la túnica de Jesús en el hombro derecho, que aparece fielmente reproducido en la copia de Sanlúcar.

En cualquier caso, sea cual fuere esa primera versión, hay que decir que se trata de una composición concebida por el Gaetano como una escena de la pasión con medias figuras. Sus claros antecedentes son los modelos de Cristo portacroce de Giovanni Bellini, Lorenzo Lotto y Sebastiano del Piombo, popularizados en Italia y Espańa. Entre los italianos lo cultivaron Tiziano y Girolamo Muziano. En Espańa fue una imagen ampliamente repetida, siguiendo el modelo de Sebastiano, por Luis de Morales, quien en una de sus versiones, conservada en el Museo de Arte de Basilea, emplea una composición significativamente parecida a la pintura de Sanlúcar, aunque invertida con respecto a esta; lógicamente de cronología bastante anterior a nuestra obra.

Desconocemos a ciencia cierta la procedencia de la versión que presentamos, pero le suponemos vinculación con los duques de Medina Sidonia, que ejercieron un continuo patrocinio artístico sobre la Iglesia Mayor de Sanlúcar, que se encontraba adosada a su palacio y que, de hecho, estaba comunicada con él mediante una tribuna, que en realidad era la prolongación de su Capilla Palatina. Lo cierto es que se desconoce la procedencia de nuestra pintura, pero existen varias posibilidades admisibles que apuntan cómo

\footnotetext{
7. MONTES GONZÁLEZ, Francisco, "El camino del Calvario de Scipione Pulzone. Un laberinto de espejos", ponencia pronunciada en A Cópia Pictórica Em Portugal, Espanha e no Novo Mundo. 1552-1752, Lisboa, Fundación Calouste Gulbenkian, 11-12 octubre de 2016.

8. Número de inventario: 4231.
} 


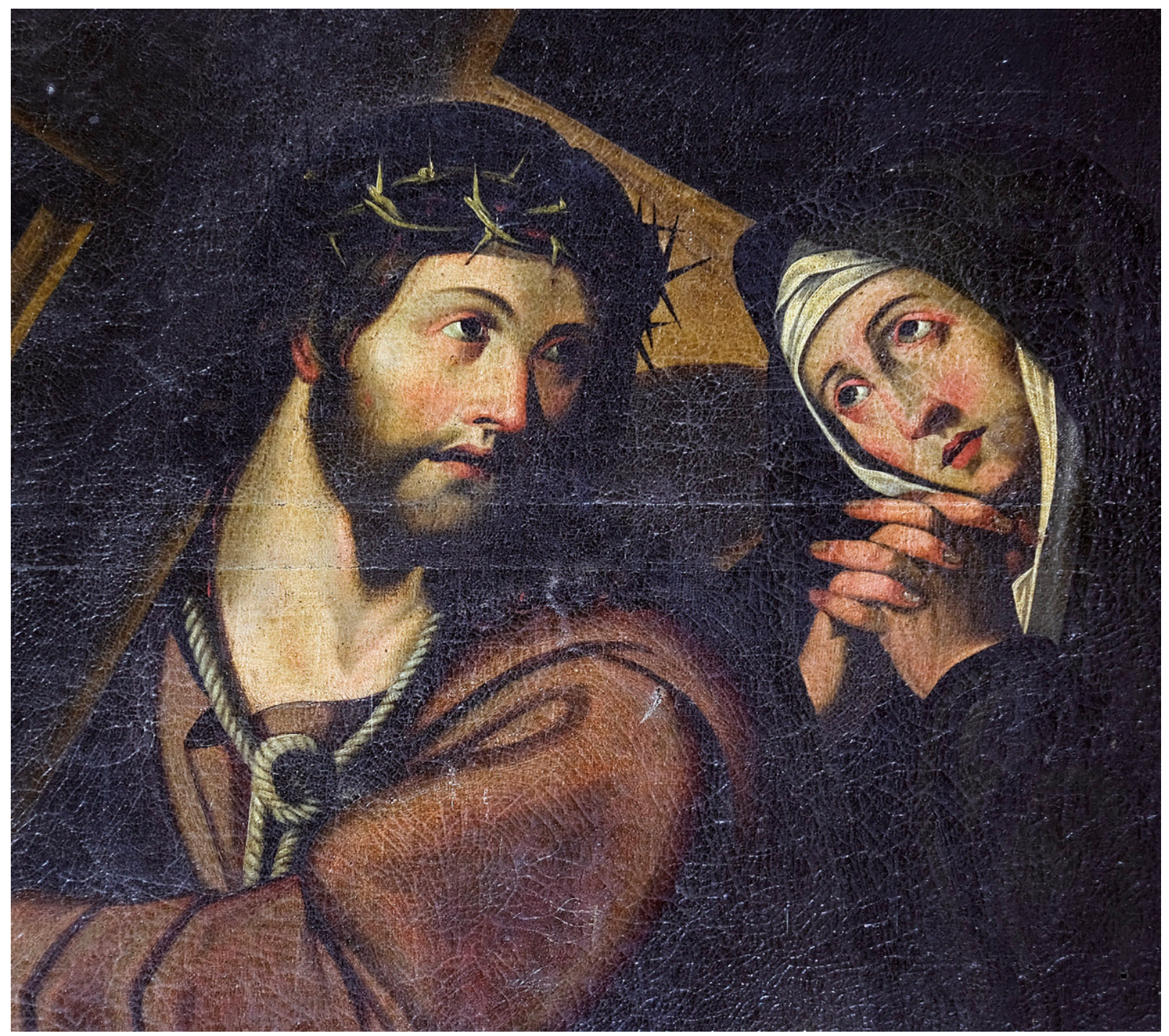

Fig. 2. Encuentro de Jesús y la Virgen de camino al Calvario (detalle). Foto de Óscar Franco ๑.

pudo llegar a Sanlúcar. Conviene recordar que desde 1779 la casa de Medina Sidonia recayó por herencia en los marqueses de Villafranca del Bierzo, del linaje Toledo. Precisamente esta familia está directamente emparentada con los duques de Paliano y con los Grandes Duques de Florencia, respectivos propietarios de dos de las versiones originales de Pulzone. El IV marqués de Villafranca, García Álvarez de Toledo (1514-1577), casó con Vittoria Colonna, hermana del III duque de Paliano, propietario de la primera versión realizada por Pulzone. Asimismo, la hermana del marqués, Leonor de Toledo, casó con el II duque de Florencia, Cosme de’ Medici (1519-1574), quienes fueron los padres de Ferdinando de’ Medici, cardenal, III Gran duque de Toscana y dueño de la otra versión. Estos vínculos familiares pudieron facilitar el conocimiento de la pintura en España, a través de copias. Sin embargo, a pesar de estos lazos de sangre, nos inclinamos a pensar que nuestro ejemplar no fue una donación de los Villafranca a la Iglesia Mayor sanluqueña, pues las dádivas que 
los Toledos hicieron al templo fueron tardías y mucho menos intensas que las realizadas por los Guzmanes, vinculados secularmente al lugar.

Explorando el entorno de los Guzmanes, hay que decir que sabemos que Pulzone retrató en Roma al II conde de Olivares y a su esposa, ciudad en la que este Guzmán, nieto del III duque de Medina Sidonia, era embajador de España ante la Santa Sede. La noticia nos la trasmite de nuevo Pacheco en su tratado, donde dice: "También he visto celebrar (con razón) dos retratos, de medios cuerpos, que Cipión Gaetano" hizo en Roma, de los dignisimos padres del gran Conde-Duque, por las cuales le enviaron al artifice trescientos escudos para colores y respondió que los recibía pero no por paga"10. Lo cierto es que sabemos que en el círculo de los Guzmanes hubo tráfico de objetos artísticos y suntuarios desde Roma a Andalucía, entre ellos pinturas. Ejemplo de ello son las reliquias de San Eutiquio y el gran lienzo de San Pedro pintado por Pasquale Cati (ha. 1520-ha. 1620), que el segundo Olivares donó en 1600 al panteón de los Medina Sidonia ${ }^{11}$, para colocarlos sobre la tumba de su abuelo, el III duque. Por ello, tampoco hay que descartar que la pintura de Sanlúcar pudiera haber llegado a los Medina Sidonia a través de los Olivares, instalados en Roma, pudiendo estar basada en la versión de la Villa Medici.

Asimismo, hemos documentado que el propio duque de Medina Sidonia, D. Manuel de Guzmán y Silva, octavo de dicho título, libró 120.522 maravedíes (unos 321 ducados) el 24 de marzo de 1617 "para las láminas que tiene dadas a pintar Don Juan de Zúniga". En el lenguaje de la época las láminas eran lo que hoy conocemos como pinturas de pequeño o mediano formato. Por entonces, Juan de Zúniga era el agente de los negocios del duque en Roma ${ }^{12}$, por lo que debemos entender que estas pinturas se estaban copiando en la ciudad italiana, pues de hecho en el documento se menciona al difunto Dr. Jerónimo de Leiva, como residente en dicha ciudad. Parece que en esto estuvo implicado D. Juan de la Sal, obispo de Bona y auxiliar del arzobispo de Sevilla, al que se le habían pagado 2.000 reales el 20 de marzo para que se los diese a Juan de Zúñiga "por el cuidado de los negocios de Su Excelencia en Roma"13. De haber sido así, no sería la primera vez que el obispo de Bona interviniera como una especie de asesor artístico del VIII duque. D. Juan de la Sal debió de ser un gran conocedor en materia artística, como indica su conocida intervención en la realización de las pinturas del retablo mayor de la iglesia de la Anunciación de Sevilla, donde aparentemente insatisfecho con lo pintado por Girolamo Lucenti de Correggio y Antonio Mohedano, acabó imponiendo a Juan de Roelas. Asimismo todo indica que el obispo de Bona ${ }^{14}$ estaba dentro de la red clientelar del duque de Medina ${ }^{15}$, como manifiesta la carta que dirigió a D. Manuel con relación a la compra de pinturas que le hizo en 1618, misiva que concluyó diciéndole: "deseo haber acertado en esta menudencia de que poder colegir Vuestra Excelencia cuán más solicito seré en las cosas de más importancia en su servicio"16.

9. Scipione Pulzone, natural de Gaeta, era llamado por ello "Il Gaetano".

10. PACHECO, Francisco, Arte de la Pintura, op. cit., fol. 443.

11. RESPALDIZA LAMA, Pedro José, "San Isidoro del Campo (1301-2002). Fortaleza de la espiritualidad y santuario del poder", Actas Simposio "San Isidoro del Campo, 1301-2002", Sevilla, Consejería de Cultura, 2004, págs. 196-197.

12. SALAS ALMELA, Luis, Medina Sidonia: el poder de la aristocracia, 1580-1670, Madrid, editorial Marcial Pons, 2008, pág. 472.

13. Archivo General de la Fundación Casa de Medina Sidonia (AGFCMS), legajo 2922, Cuentas de Diego Ruiz de Salazar, Cristóbal de Bilbao, Francisco Caballero y Pedro de Amaya, Agentes de la casa del duque mi señor en Sevilla de los años de 1615 y 1616, sin foliar.

14. Se trata de la actual ciudad de Annaba, en Argelia, anteriormente conocida como Hipona y Bona.

15. Sobre D. Juan de la Sal, véase BONNEVILLE, Henry, "Dos testimonios inéditos de don Juan de la Sal, obispo de Bona, sobre la vida en Sevilla (1623-1626)", W.AA., Hommage des hispanistes français à Nöel Salomon, Barcelona, Ed. Laia, 1979, págs. 109-122. PONCE CÁRDENAS, Jesús, "Góngora y el conde de Niebla: las sutiles gestiones del mecenazgo", Criticón, n. ${ }^{\circ} 106,2009$, págs. 99-146.

16. AGFCMS, legajo 2965. Cuentas de la tesorería y agencia de Sevilla. Año de 1618. Tomo 16, sin foliar. 


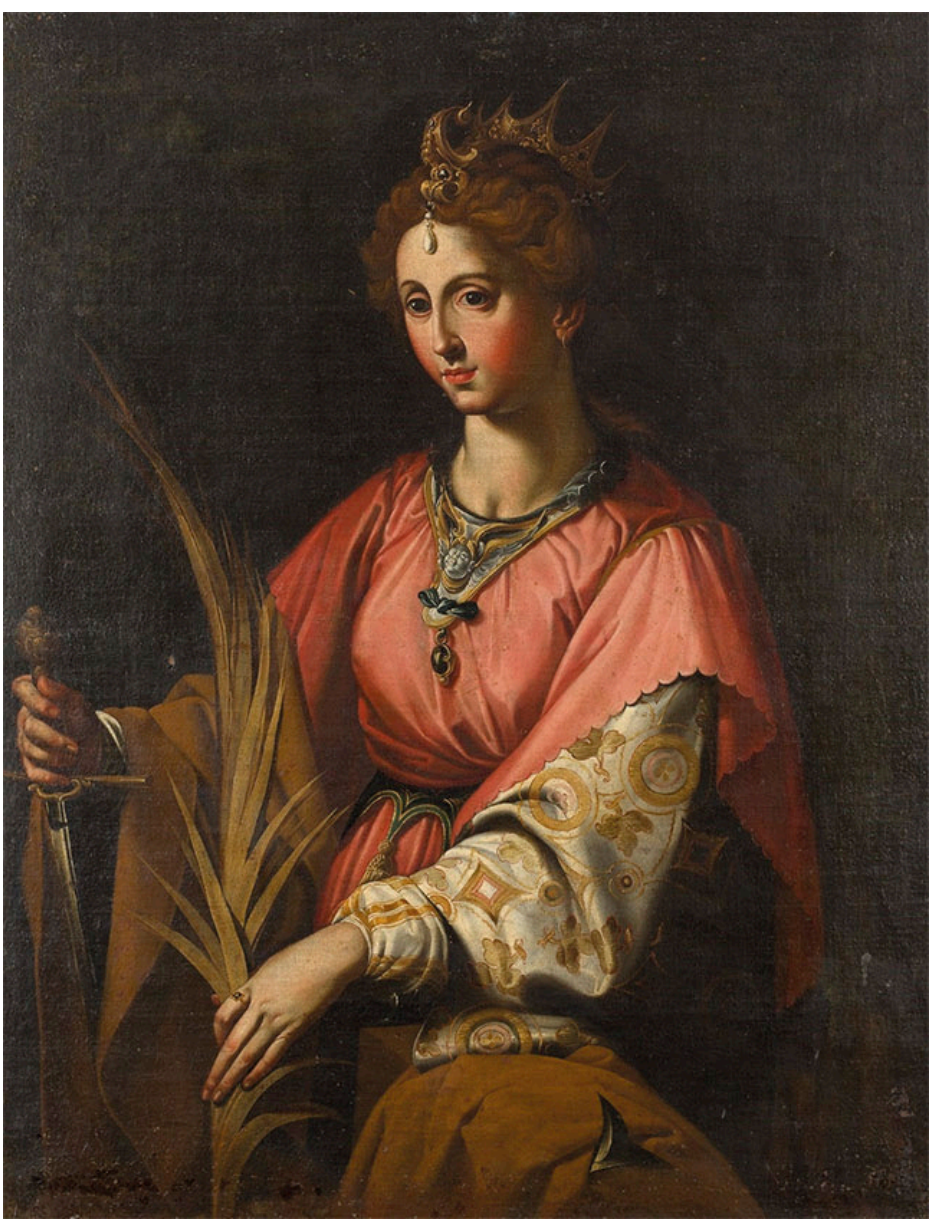

Fig. 3. Santa Catalina de Alejandría, Francisco Pacheco, Mercado de Arte.

Estos nuevos datos documentales parecen sugerir, al menos en lo que respecta al copiado de obras romanas, que los Medina Sidonia pudieron tener en fechas tempranas un papel protagonista a través de sus agentes en Roma. Hasta ahora, a la hora de explicar la presencia de pintura italiana en la Sevilla del primer tercio del XVII, se había citado con acierto la colección de los duques de Alcalá ${ }^{17}$, pero se había desconsiderado por falta de datos concretos el protagonismo que pudieron tener los Guzmanes mayores, limitándolo a la rama menor de los condes de Olivares. Esperamos poder desarrollar en el futuro el papel que, en materia artística, los Guzmanes andaluces tuvieron en fechas tempranas a través de sus agentes y parientes en Roma.

También es cierto que la obra que presentamos pudo llegar a Sanlúcar procedente de la Corte, donde los Guzmanes tenían agentes ${ }^{18}$, en cuyo caso sería un trasunto de la versión del secretario Vázquez. De hecho, nuestra copia nos parece una obra realizada en España. Lo evidente es que todas estas oportunidades existieron y deben tenerse en cuenta. No obstante, la posibilidad más sencilla es que la pintura fuera copiada a partir de 1607, cuando la pintura propiedad de Vázquez de Leca llegó a Sevilla procedente de la Corte. No en vano, el interés hispalense por la obra de Pulzone queda demostrado por la copia que se conserva en la Catedral de su Crucifixión ${ }^{19}$, cuya composición original fue realizada para la iglesia de Santa María in Vallicella de Roma. Si en Sevilla ya existía al menos una copia de Pulzone, no sería descabellado que algún pintor local copiara un original suyo que tenía a la mano, bien por iniciativa propia o como encargo de algún particular; en el caso de nuestra obra, por voluntad de los Guzmanes. Lo cierto es que, a falta de datos fehacientes, esta parece la hipótesis más sencilla.

El pintor sevillano que debió copiar el original de Pulzone materializó una versión simplificada del mismo, prescindiendo de todas las figuras secundarias, quedándose sólo con Cristo y la Virgen. Unió sus

\footnotetext{
17. SALORT PONS, Salvador, "Las relaciones artísticas entre Italia y Sevilla durante el primer tercio del siglo XVII", VV.AA., De Herrera a Velázquez: el primer naturalismo en Sevilla, Catálogo de la exposición, Sevilla, Fundación Focus-Abengoa, 2005, págs. 53-67.

18. SALAS ALMELA, Luis, "La agencia en Madrid del VIII duque de Medina Sidonia, 1615-1636", Hispania. Revista Española de Historia, vol. 66, n. ${ }^{\circ} 224,2006$, págs. 909-958.

19. VALDIVIESO GONZÁLEZ, Enrique, Catálogo de las pinturas de la Catedral de Sevilla, Sevilla, Enrique Valdivieso, 1978, pág. 47, lám. XX.
} 
figuras y cambió el formato, acercándolo al propio de las imágenes de devoción privada. De esta manera, convirtió una escena abigarrada y tumultuosa en otra donde predomina la sobriedad. Además, suprimió el pequeño paisaje de fondo, evitando cualquier distracción del espectador. Es evidente que en la versión de Sanlúcar se ha adaptado el original italiano al "gusto español" y a su predilección por el patetismo, dando como resultado una composición similar a la citada pintura de Morales, conservada en Basilea, de cronología muy anterior. De hecho, el pintor sevillano que copió la obra no fue un mero copista, sino que dejó su sello en ella, cambiando además la postura de las manos de Cristo, la forma de la corona de espinas, así como el color de la túnica y la forma de sus pliegues. Resulta muy significativo que el copista introdujera un manto cubriendo a Cristo que no está en el original. Esto podría ponerse en relación con la recomendación que Pacheco hace en su tratado sobre la manera de representar a Jesús con la cruz a cuestas, diciendo que Cristo debe llevar dos vestiduras; a saber, "la túnica inconsútil ceñida que [...] hizo y le puso su [...] madre en la niñez y el manto con que se cubrian los hebreos"20.

¿Podría ser esta pintura de Sanlúcar una copia del taller de Pacheco? ¿A qué otro pintor activo en Sevilla hacia 1607 la podemos atribuir? Estas son cuestiones que no tienen una respuesta satisfactoria pero merece la pena que se planteen. Sabemos que Pacheco tuvo relación con la casa de Medina Sidonia al menos desde 1609, y que en 1617 firmó una obra para el convento de Santo Domingo de Sanlúcar ${ }^{21}$. Asimismo, sabemos que Pacheco fue creador de sus composiciones, pero también que usó estampas, se basó en obras de otros maestros y copió literalmente al menos dos pinturas: la Virgen de Belén de Marcellus Coffermans y el Cristo de los ajusticiados de Luis de Vargas. La admiración con que el sanluqueño habla en su tratado del original de Pulzone y el profundo conocimiento de la obra que trasluce su pormenorizada descripción, bien podrían derivar de haber convivido directamente con ella mientras la copiaba, posibilidad que sugerimos. Además, la reciente aparición en el mercado de una Santa Catalina de Alejandría (Fig. 3) de mano de Pacheco ${ }^{22}$, también presenta un fondo oscuro similar al de la copia que aquí hemos presentado. La Santa Catalina, cuyo preciosismo en la vestimenta y protagonismo de la figura prefiguran las santas de Zurbarán, y la copia de Pulzone, parecen indicarnos que el artista sanluqueño tuvo una tímida incursión en la estética tenebrista, aspecto este, que si bien no pasa de ser anecdótico, hasta ahora parecía totalmente ajeno a su arte.

Bibliografía

BONNEVILLE, Henry, "Dos testimonios inéditos de don Juan de la Sal, obispo de Bona, sobre la vida en Sevilla (1623-1626)”, VV.AA., Hommage des hispanistes français à Nöel Salomon, Barcelona, Ed. Laia, 1979, págs. 109-122.

MONTES GONZÁLEZ, Francisco, "El camino del Calvario de Scipione Pulzone. Un laberinto de espejos", ponencia pronunciada en A Cópia Pictórica Em Portugal, Espanha e no Novo Mundo. 1552-1752, Lisboa, Fundación Calouste Gulbenkian, 11-12 octubre de 2016.

PACHECO, Francisco, Arte de la Pintura, Sevilla, 1649.

PONCE CÁRDENAS, Jesús, “Góngora y el conde de Niebla: las sutiles gestiones del mecenazgo”, Criticón, n. ${ }^{\circ}$ 106, 2009, págs. 99-146.

20. PACHECO, Francisco, Arte de la Pintura, op. cit., fols. 538-539.

21. ROMERO DORADO, Antonio, "Un nuevo Santo Tomás de Aquino de Francisco Pacheco", Laboratorio de Arte, n. ${ }^{\circ} 29,2017$, págs. 803-810.

22. VALDIVIESO, Enrique, "Santa Catalina de Alejandría, de Francisco Pacheco", Catálogo de Isbilya. Venta Directa, octubre, 2018. Sevilla, 2018, sin paginar. 
RESPALDIZA LAMA, Pedro José, "San Isidoro del Campo (1301-2002). Fortaleza de la espiritualidad y santuario del poder", Actas Simposio “San Isidoro del Campo, 1301-2002”, Sevilla, Consejería de Cultura, 2004, págs. 196-197.

ROMERO DORADO, Antonio, “Un nuevo Santo Tomás de Aquino de Francisco Pacheco", Laboratorio de Arte, n. ${ }^{\circ}$ 29, 2017, págs. 803-810.

SALAS ALMELA, Luis, "La agencia en Madrid del VIII duque de Medina Sidonia, 1615-1636", Hispania. Revista Española de Historia, vol. 66, n. ${ }^{\circ} 224,2006$, págs. 909-958.

SALAS ALMELA, Luis, Medina Sidonia: el poder de la aristocracia, 1580-1670, Madrid, editorial Marcial Pons, 2008.

SALORT PONS, Salvador, "Las relaciones artísticas entre Italia y Sevilla durante el primer tercio del siglo XVII", VV.AA., De Herrera a Velázquez: el primer naturalismo en Sevilla, Catálogo de la exposición, Sevilla, Fundación Focus-Abengoa, 2005, págs. 53-67.

VALDIVIESO GONZÁLEZ, Enrique, Catálogo de las pinturas de la Catedral de Sevilla, Sevilla, Enrique Valdivieso, 1978.

VALDIVIESO GONZÁLEZ, Enrique y SERRERA CONTRERAS, Juan Miguel, Pintura sevillana del primer tercio del siglo XVII, Madrid, Consejo Superior de Investigaciones Científicas, 1985.

VALDIVIESO, Enrique, "Santa Catalina de Alejandría, de Francisco Pacheco", Catálogo de Isbilya. Venta Directa, octubre, 2018. Sevilla, 2018, sin paginar.

VANNUGLI, Antonio, "La subida al Calvario de Scipione Pulzone para Marcantonio Colonna", Archivo Español de Arte, vol. 85, n. ${ }^{\circ} 340$, 2012, págs. 303-328. 